\title{
Microstructure and Mechanical Properties of $\left(\mathrm{Zr}_{0.5} \mathrm{Cu}_{0.4} \mathrm{Al}_{0.1}\right)_{100-x} \mathrm{Ta}_{x}$ Bulk Metallic Glass Composites
}

\author{
Koji Okazaki $^{1, * 1}$, Wei Zhang ${ }^{2, * 2}$ and Akihisa Inoue ${ }^{2}$ \\ ${ }^{1}$ Graduate school, Tohoku University, Sendai 980-8577, Japan \\ ${ }^{2}$ Institute for Materials Research, Tohoku University, Sendai 980-8577, Japan
}

\begin{abstract}
We investigated the microstructure and mechanical properties of $\left(\mathrm{Zr}_{0.5} \mathrm{Cu}_{0.4} \mathrm{Al}_{0.1}\right)_{100-x} \mathrm{Ta}_{x}(x=0-12)$ bulk metallic glass composites containing dispersed Ta-rich dendrites prepared by copper mold casting. With increasing Ta content, the volume fraction of the dendrite particle increases, while other crystalline phases are precipitated in the Ta content range of over 9 at $\%$. The compressive fracture strength and plastic strain of the composites significantly increase from $1890 \mathrm{MPa}$ and $0.7 \%$, respectively, for the $x=0$ alloy to $2180 \mathrm{MPa}$ and $15.9 \%$, respectively, for $x=9$ alloy, and then significantly decrease with further increasing Ta content. The improvement of plasticity is attributed to an increase in the density of shear bands before final fracture resulting from the increase of the fracture strength. [doi:10.2320/matertrans.47.2571]
\end{abstract}

(Received July 24, 2006; Accepted August 31, 2006; Published October 15, 2006)

Keywords: bulk metallic glass composite, dendrite, tantalum content, mechanical property, shear band

\section{Introduction}

Since the first report on the synthesis of a bulk metallic glass in a special multi-component alloy system prepared by the copper mold casting method in $1989,{ }^{1)}$ a number of bulk metallic glasses (BMGs) have been found in various multicomponent alloy systems ${ }^{2-4)}$ and attracted much engineering interests. BMGs exhibit yield strengths greatly exceeding those for conventional high-strength crystalline alloys, ${ }^{5)}$ together with additional desirable properties, such as low Young's modulus and a nearly constant large elastic strain of about $2 \%$. However, their applications have been limited, because of the absence of macroscopic distinct plastic strain before fracture.

Recent attempts to ductilize BMGs have been focused on the preparation of composite materials consisting of crystalline phases dispersed in the metallic glass matrix. One can notice the following preparation methods, i.e., homogeneous dispersion of nanocrystals through partial devitrification of BMGs, ${ }^{6,7)}$ addition of the crystalline particles to the melt prior to casting, ${ }^{8,9)}$ casting of a glass-forming alloy liquid to crystalline particles or fiber pre-form, ${ }^{10)}$ solidification of a glassy phase containing in situ formation of nanoscale or microscale crystalline phases from the melt during casting. ${ }^{11-19)}$

Recently, the BMG composites containing micrometerscale Ta-rich dendritic precipitates have gained considerable interest because the composites for $\mathrm{Zr}$ - and $\mathrm{Cu}$-based alloys exhibit large plastic strain exceeding $10 \%^{16-19)}$ which are useful for engineering materials. However, little is known about the effect of additional Ta content on the microstructure, composition, thermal stability and mechanical properties of the BMG composites. It is known that the dendritic precipitates are always concomitant with the partitioning process of constituent elements into the growing dendrites during cooling. The composition and volume

\footnotetext{
${ }^{* 1}$ Graduate Student, Tohoku University. Present address: TOSOH COR-

PORATION, Yamaguchi 746-8501, Japan

${ }^{* 2}$ Corresponding author, E-mail: wzhang@imr.tohoku.ac.jp
}

fraction of the precipitation phases are dominated by partitioning process of the constituent elements from the glassy matrix to the precipitation phase. The partitioning process is strongly dependent on the constituent elements, solubility limit, alloy concentration, and so on. The control of these parameters is expected to cause the change in the mechanical properties and thermal stability of the composites through the structural and compositional variations. It is important to investigate the influence of the constituent concentration on the structure and mechanical properties of the BMG composites containing dendrites. In this paper, we present successful syntheses of in-situ formed $\left(\mathrm{Zr}_{0.5} \mathrm{Cu}_{0.4^{-}}\right.$ $\left.\mathrm{Al}_{0.1}\right)_{100-x} \mathrm{Ta}_{x}(x=0-12)$ BMG composites containing Tarich dendrites prepared by copper mold casting and investigate the effect of $\mathrm{Ta}$ content on the microstructure, composition, thermal stability, and mechanical properties of the BMG composites.

\section{Experimental Procedure}

Master alloy ingots with composition of $\left(\mathrm{Zr}_{0.5} \mathrm{Cu}_{0.4^{-}}\right.$ $\left.\mathrm{Al}_{0.1}\right)_{100-x} \mathrm{Ta}_{x}(x=0,3,6,9,12)$ were prepared from high purity raw metals by arc melting in an argon atmosphere. At first the binary Zr-Ta alloy was prepared. This binary alloy was then remelted with $\mathrm{Cu}$ and $\mathrm{Al}$. Remelted ingots were cast into a copper mold to produce a cylindrical rod form with a length of $50 \mathrm{~mm}$ and a diameter of $2.0 \mathrm{~mm}$. The structure was identified by X-ray diffraction, optical microscopy (OM) and scanning electron microscopy (SEM). The analyses of the components in the constituent phases were made by energy dispersive spectroscopy (EDX). Thermal stability associated with glass transition and crystallization temperatures was examined by differential scanning calorimetry (DSC) at a heating rate of $0.67 \mathrm{~K} / \mathrm{s}$. Mechanical properties were measured with an Instron-type testing machine. The gauge dimension was $2 \mathrm{~mm}$ in diameter and $4 \mathrm{~mm}$ in height for compressive test and the strain rate was $5 \times 10^{-4} \mathrm{~s}^{-1}$. Fracture surface was examined by SEM. 


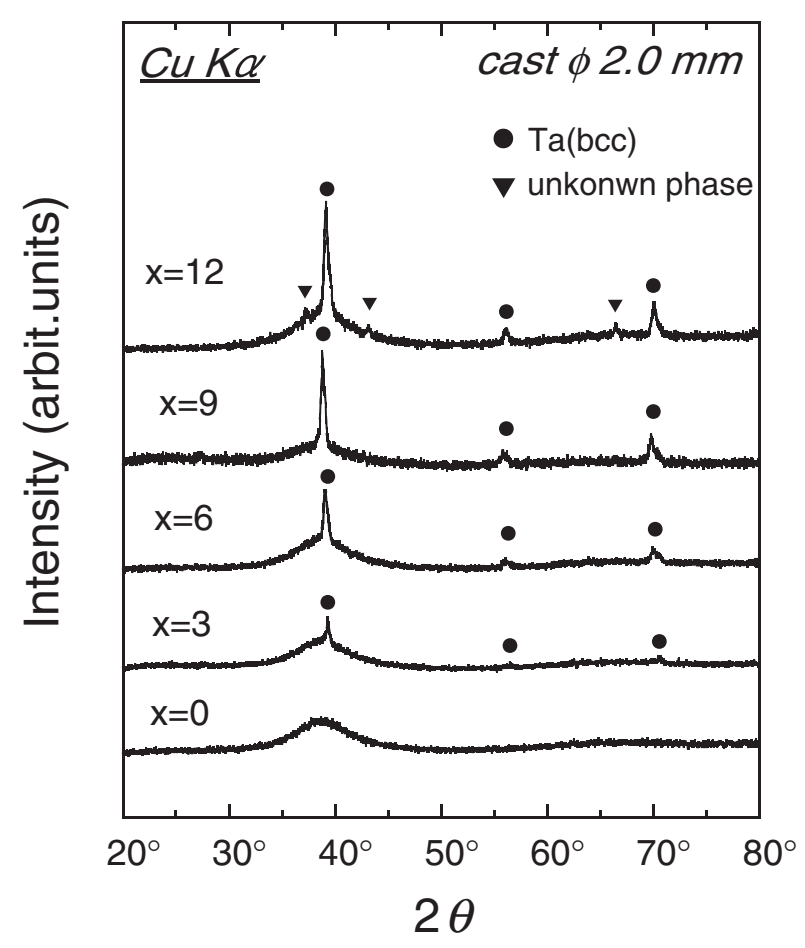

Fig. 1 X-ray diffraction patterns of as-cast $\left(\mathrm{Zr}_{0.5} \mathrm{Cu}_{0.4} \mathrm{Al}_{0.1}\right)_{100-x} \mathrm{Ta}_{x}$ $(x=0-12)$ alloy rods with a diameter of $2 \mathrm{~mm}$ produced by copper mold casting.

\section{Results}

Figure 1 shows XRD patterns of the as-cast $\left(\mathrm{Zr}_{0.5} \mathrm{Cu}_{0.4^{-}}\right.$ $\left.\mathrm{Al}_{0.1}\right)_{100-x} \mathrm{Ta}_{x}(x=0,3,6,9,12)$ alloy rods with a diameter of $2.0 \mathrm{~mm}$. The XRD pattern of the $x=0$ alloy rod shows a broad halo peak, characteristic of a glassy phase, while those of the $\left(\mathrm{Zr}_{0.5} \mathrm{Cu}_{0.4} \mathrm{Al}_{0.1}\right)_{100-x} \mathrm{Ta}_{x}(x=3-12)$ alloys consist of $\mathrm{a}$ broad halo peak superimposed with the sharp diffraction peaks of a Ta (bcc) phase for $x=3-9$ alloys, and Ta (bcc) plus unknown crystalline phases for $x=12$ alloy. With increasing Ta content, the intensity of the bcc-Ta phase peaks also increases, indicating an increase of the volume fraction of the bcc-Ta precipitation phase. Figure 2 shows optical microscopy (OM) images of the $\left(\mathrm{Zr}_{0.5} \mathrm{Cu}_{0.4} \mathrm{Al}_{0.1}\right)_{100-x} \mathrm{Ta}_{x}$ $(x=3,6,9,12)$ alloy rods. It can be seen that the dendritic precipitation phases disperse homogeneously in the glassy matrix, and the volume fraction of bcc-Ta dendritic phase gradually increases with increasing Ta content. Table 1 lists EDS analytical compositions of the dendrites and glassy matrix in the $\left(\mathrm{Zr}_{0.5} \mathrm{Cu}_{0.4} \mathrm{Al}_{0.1}\right)_{100-x} \mathrm{Ta}_{x}$ BMG composites. The dendrites have Ta-rich and Al-free compositions, and the chemical composition of the dendrite phases is in the range of $88.8-90.1$ at\% $\mathrm{Ta}, 5.4-7.5$ at\% $\mathrm{Zr}$ and $2.4-5.8$ at\% $\mathrm{Cu}$. Table 1 also shows that the Ta and $\mathrm{Zr}$ concentrations of the dendrite phase gradually decrease, which the $\mathrm{Cu}$ concentration increases with increasing volume fraction of the dendrite, accompanying the gradual increase of Ta concentration in the glassy matrix.

Figure 3 shows DSC curves of the as-cast $\left(\mathrm{Zr}_{0.5} \mathrm{Cu}_{0.4^{-}}\right.$ $\left.\mathrm{Al}_{0.1}\right)_{100-x} \mathrm{Ta}_{x}$ BMG composites. All the alloys exhibit a distinct glass transition, followed by a supercooled liquid region and then exothermic reactions due to crystallization. The glass transition temperature $\left(T_{g}\right)$ and crystallization temperature $\left(T_{x}\right)$ increase monotonously with increasing Ta content to 12 at $\%$, while the supercooled liquid region $\Delta T_{x}\left(=T_{x}-T_{g}\right)$ decreases from $77 \mathrm{~K}$ to $70 \mathrm{~K}$. It is also noticed that the heat of crystallization $\left(\Delta H_{x}\right)$ of the alloys

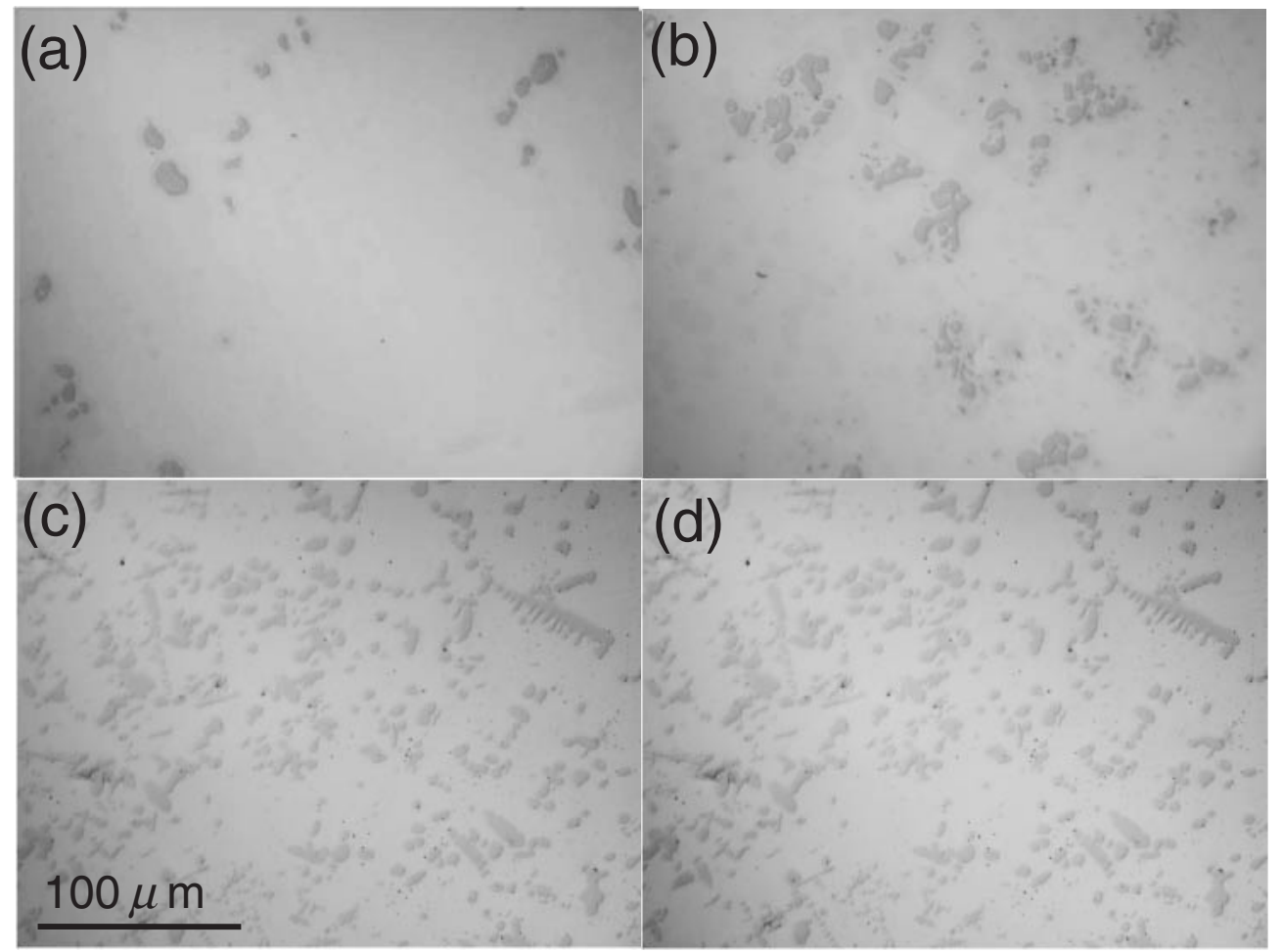

Fig. 2 Optical micrograph of the transverse cross section of as-cast $\left(\mathrm{Zr}_{0.5} \mathrm{Cu}_{0.4} \mathrm{Al}_{0.1}\right)_{100-x} \mathrm{Ta}_{x}$ alloy rods with a diameter of $2.0 \mathrm{~mm} . x=3$ (a), $x=6$ (b), $x=9$ (c), $x=12$ (d). 
Table 1 Compositions of $\left(\mathrm{Zr}_{0.5} \mathrm{Cu}_{0.4} \mathrm{Al}_{0.1}\right)_{100-x} \mathrm{Ta}_{x} \quad(x=0,3,6,9,12)$ BMG composites obtained by EDS.

\begin{tabular}{|c|c|c|c|c|c|}
\hline alloy & phase & $\begin{array}{c}\mathrm{Zr}, \\
(\mathrm{at} \%)\end{array}$ & $\begin{array}{c}\mathrm{Cu}, \\
(\mathrm{at} \%)\end{array}$ & $\begin{array}{c}\mathrm{Al}, \\
(\mathrm{at} \%)\end{array}$ & $\begin{array}{c}\mathrm{Ta}, \\
\text { (at\%) }\end{array}$ \\
\hline & Nominal composition & 50.0 & 40.0 & 10.0 & \\
\hline$x=0$ & Average composition of BMG & 53.4 & 37.3 & 9.3 & - \\
\hline \multirow{3}{*}{$x=3$} & Nominal composition & 48.5 & 38.8 & 9.7 & 3.0 \\
\hline & BMG matrix & 53.9 & 32.6 & 11.8 & 1.7 \\
\hline & Dendrite & 7.5 & 2.4 & 0.0 & 90.1 \\
\hline \multirow{3}{*}{$x=6$} & Nominal composition & 47.0 & 37.6 & 9.4 & 6.0 \\
\hline & BMG matrix & 53.1 & 33.7 & 10.9 & 2.3 \\
\hline & Dendrite & 7.1 & 2.9 & 0.0 & 90.0 \\
\hline \multirow{3}{*}{$x=9$} & Nominal composition & 45.5 & 36.4 & 9.1 & 9.0 \\
\hline & BMG matrix & 52.6 & 34.5 & 10.4 & 2.5 \\
\hline & Dendrite & 5.7 & 5.1 & 0.0 & 89.2 \\
\hline \multirow{3}{*}{$x=12$} & Nominal composition & 44.0 & 35.2 & 8.8 & 12.0 \\
\hline & BMG matrix & 51.9 & 35.8 & 9.4 & 2.9 \\
\hline & Dendrite & 5.4 & 5.8 & 0.0 & 88.8 \\
\hline
\end{tabular}

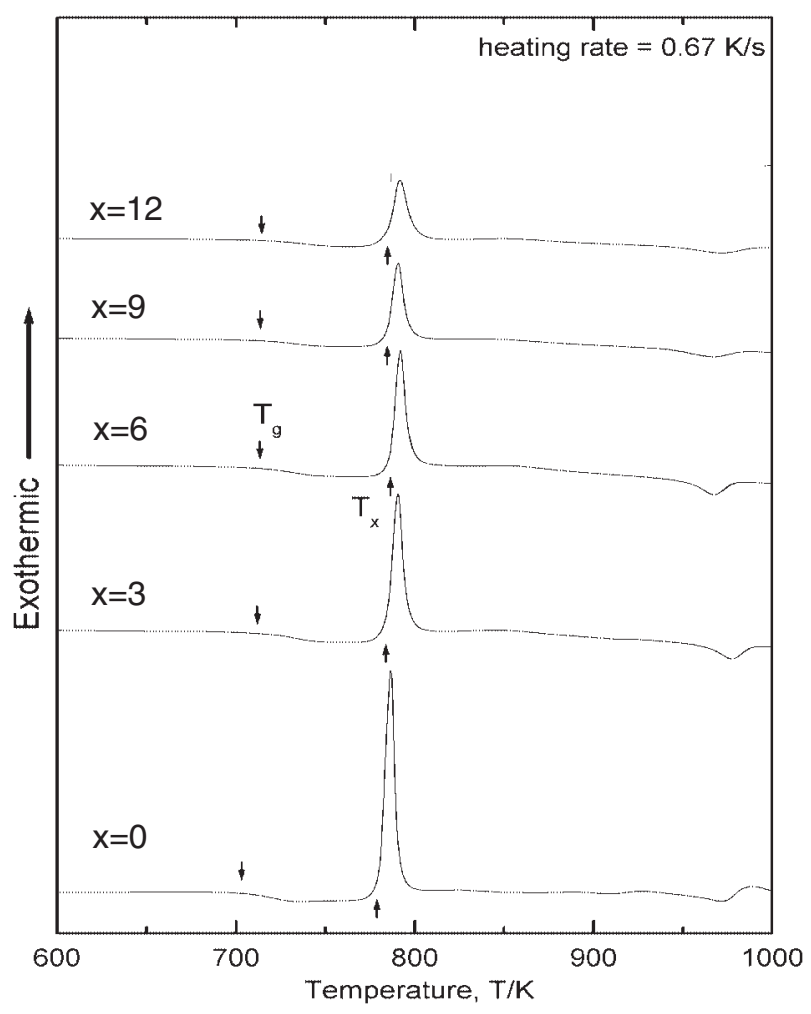

Fig. 3 DSC curves of as-cast $\left(\mathrm{Zr}_{0.5} \mathrm{Cu}_{0.4} \mathrm{Al}_{0.1}\right)_{100-x} \mathrm{Ta}_{x}(x=0-12)$ alloy rods with a diameter of $2.0 \mathrm{~mm}$.

gradually decreases with increasing Ta content, indicating that the volume fraction of the glassy phase in the BMG composites gradually decreases. This result is also consistent with that obtained by XRD and OM.

Figure 4 shows compressive stress-strain curves of the $\left(\mathrm{Zr}_{0.5} \mathrm{Cu}_{0.4} \mathrm{Al}_{0.1}\right)_{100-x} \mathrm{Ta}_{x}(x=0-12)$ BMG composites. The compressive fracture strength $\left(\sigma_{\mathrm{f}}\right)$ and plastic strain $\left(\varepsilon_{\mathrm{f}}\right)$ are $1890 \mathrm{MPa}$ and $0.7 \%$, respectively, for the $\mathrm{Zr}_{50} \mathrm{Cu}_{40} \mathrm{Al}_{10}$ alloy, and $2015 \mathrm{MPa}$ and $5.3 \%$, respectively for the 3 at\% Ta alloy.

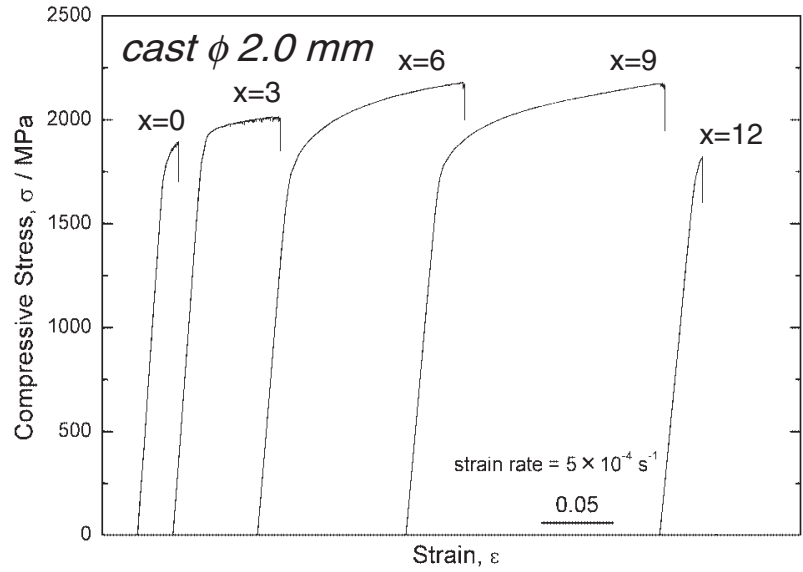

Fig. 4 Compressive stress-elongation curves of as-cast $\left(\mathrm{Zr}_{0.5} \mathrm{Cu}_{0.4^{-}}\right.$ $\left.\mathrm{Al}_{0.1}\right)_{100-x} \mathrm{Ta}_{x}(x=0-12)$ alloy rods with a diameter of $2.0 \mathrm{~mm}$.

The addition of a small amount of Ta obviously improves the fracture strength and plasticity. In particular, the plasticity increases remarkably with further increasing Ta content to 9 at $\%$. The $\sigma_{\mathrm{f}}$ and $\varepsilon_{\mathrm{p}}$ are $2175 \mathrm{MPa}$ and $12.5 \%$, respectively, for the 6 at $\% \mathrm{Ta}$ alloy, and $2180 \mathrm{MPa}$ and $15.9 \%$, respectively, for the 9 at $\%$ Ta alloy. However, the further increase of Ta content to over 9 at $\%$ causes significant decreases of $\sigma_{\mathrm{f}}$ and $\varepsilon_{\mathrm{p}}$. The $\sigma_{\mathrm{f}}$ and $\varepsilon_{\mathrm{p}}$ are $1820 \mathrm{MPa}$ and $0.2 \%$, respectively for the 12 at $\%$ Ta alloy. It is thus noticed that higher values of $\sigma_{\mathrm{f}}$ and $\varepsilon_{\mathrm{p}}$ are obtained in the Ta content range of 6 to 9 at $\%$. Figure 5 shows the outer shape of the $\left(\mathrm{Zr}_{0.5} \mathrm{Cu}_{0.4} \mathrm{Al}_{0.1}\right)_{100-x} \mathrm{Ta}_{x}(x=$ $0,3,9,12)$ BMG composite rods after compression test. The fracture of all the alloys occurred along the maximum shear stress plane, which was declined by about 45 degrees to the direction of applied load. It is also clear that the significant plastic deformation for the 9 at $\%$ Ta alloy enables plastic buckling deformation that has not been observed in the deformation behavior for the 0 and 12 at $\%$ Ta alloys. We also observed the shear bands developed on the outer surface for the BMG composite rods (Fig. 6). A few shear bands are seen on the outer surface of the $\mathrm{Zr}_{50} \mathrm{Cu}_{40} \mathrm{Al}_{10}$ alloy rod (Fig. 6(a)). The shear bands are completely parallel to the maximum shear stress direction and also agree with the direction of fracture surface. The density of shear bands increases with increasing Ta content to 9 at\%. It is noticed that a large number of shear bands are observed on the outer surface for the 6 and 9 at $\%$ Ta alloy rods, and the propagation direction of main shear bands agrees with that of maximum shear stress. In addition to the rather straight shear bands generated along the parallel direction, a number of wavy-type shear bands are also observed, indicating that the shear bands are branched by the existence of the Ta-rich dendritc particles (Figs. 6(b) and (c)). However, no trace of shear band is observed on the outer surface of the 12 at\% Ta alloy rod (Fig. 6(d)).

\section{Discussion}

As exemplified in Figs. 1 and 2, the BMG composites consisting of Ta-rich dendrite particles dispersed in the glassy matrix were fabricated for the $\left(\mathrm{Zr}_{0.5} \mathrm{Cu}_{0.4^{-}}\right.$ $\left.\mathrm{Al}_{0.1}\right)_{100-x} \mathrm{Ta}_{x}(x=3-12)$ alloys. The Ta concentration of 

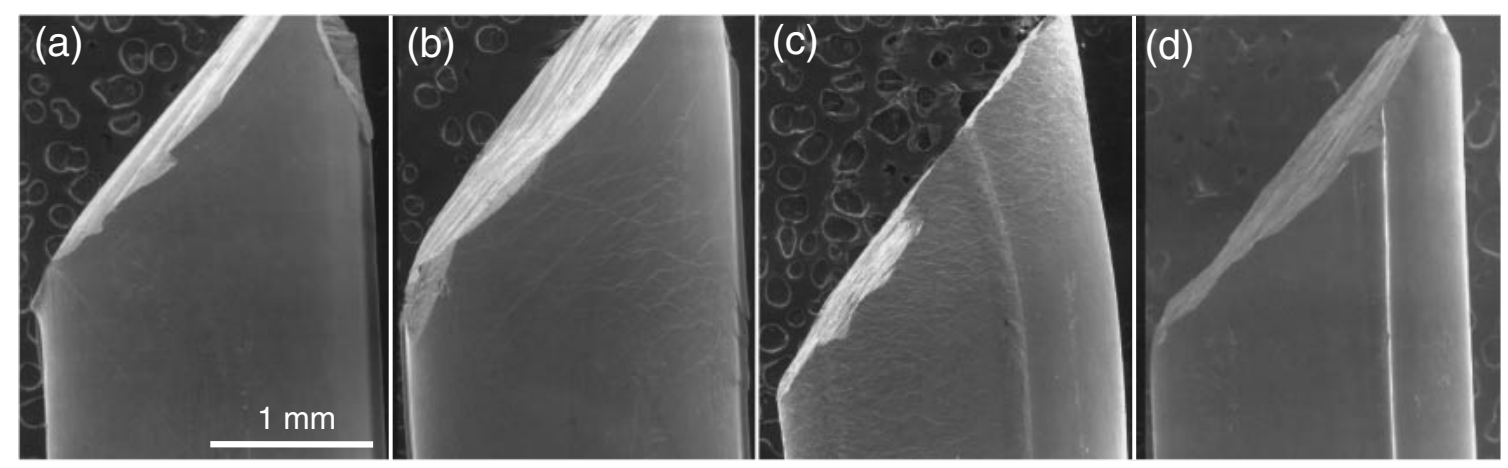

Fig. 5 SEM images of the outer shape of as-cast $\left(\mathrm{Zr}_{0.5} \mathrm{Cu}_{0.4} \mathrm{Al}_{0.1}\right)_{100-x} \mathrm{Ta}_{x}$ alloys rod with a diameter of $2.0 \mathrm{~mm}$ after compression test. $x=0$ (a), $x=3$ (b), $x=9$ (c), $x=12$ (d).
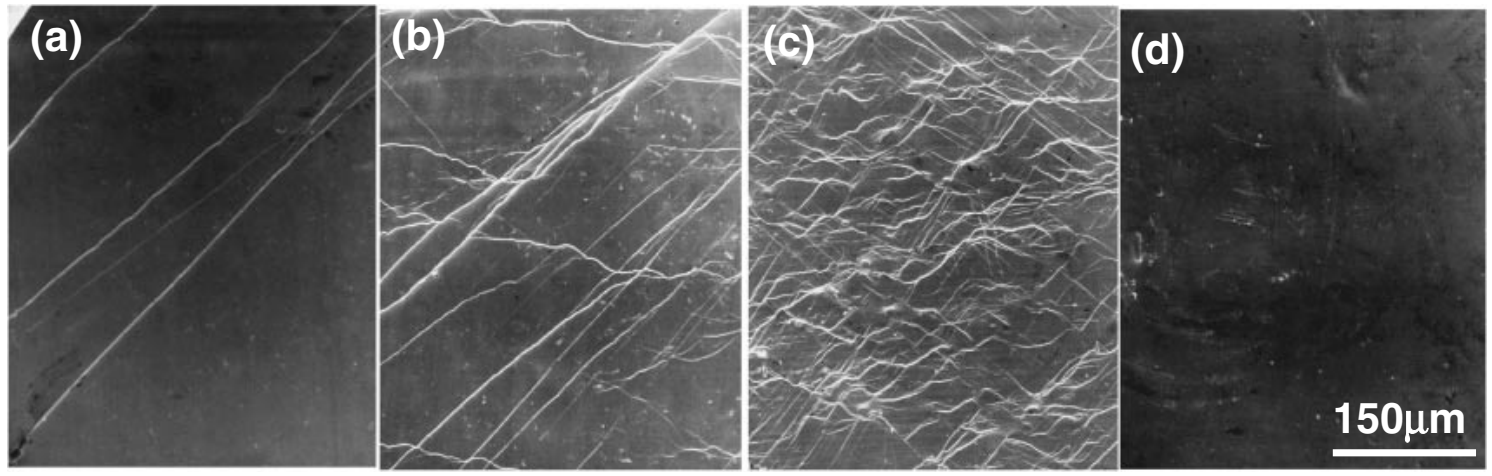

Fig. 6 The shear bands developed on the outer surface for the as-cast $\left(\mathrm{Zr}_{0.5} \mathrm{Cu}_{0.4} \mathrm{Al}_{0.1}\right)_{100-x} \mathrm{Ta}_{x}$ alloy rods with a diameter of $2.0 \mathrm{~mm}$ after compression test. $x=0$ (a), $x=3$ (b), $x=9$ (c), $x=12$ (d).

the glassy phase increases with increasing Ta content (Table 1), though the volume fraction of the Ta-rich dendrite particles also increases. The similar endothermic and exothermic reactions due to the glass transition and crystallization, respectively, were recognized for the composites. However, the supercooled liquid region $\Delta T_{x}$ decreases with increasing Ta content (Fig. 3), indicating that the stability of the glassy matrix against crystallization is reduced..$^{5,20)}$ In addition, a few unknown crystalline phases are precipitated in the glassy matrix for the $x=12$ alloy (Fig. 1), indicating that the glass-forming ability (GFA) of the glassy matrix phase is also reduced. The reason for the decrease of the thermal stability and the GFA of the $\mathrm{Zr}-\mathrm{Cu}-\mathrm{Al}$ glassy alloy containing Ta can be discussed in the framework of the three component rules. ${ }^{5,20)}$ It is known that the $\mathrm{Zr}-\mathrm{Cu}-\mathrm{Al}$ system completely satisfies the three component rules. The heat of mixing is $2 \mathrm{~kJ} / \mathrm{mol}$ for $\mathrm{Cu}-\mathrm{Ta}$ pair, $3 \mathrm{~kJ} / \mathrm{mol}$ for $\mathrm{Zr}$-Ta pair and -19 $\mathrm{kJ} / \mathrm{mol}$ for Al-Ta pair. ${ }^{21)}$ The positive heats of mixing for $\mathrm{Cu}-\mathrm{Ta}$ and $\mathrm{Zr}$-Ta pairs imply that the present alloy system does not satisfy the three component rules, resulting in the decrease in the thermal stability of supercooled liquid and the GFA.

As shown in Fig. 4, the $\sigma_{\mathrm{f}}$ and $\varepsilon_{\mathrm{p}}$ of the BMG composites significantly increases with increasing Ta content to 9 at $\%$. The reason may be attributed to the shear band-particle interactions in the glassy matrix. At the glassy matrix and Tarich particle interface, a stress concentration exists. This increasing stress mismatch between the matrix and the particles could be considered to be the reason for the particle- matrix interface being an generation site for shear band formation. In addition, Ta-rich particles can inhibit shear band propagation at large strains. ${ }^{17)}$ Obviously, the generation and interaction of shear bands by particles would result in more and more shear bands arising during deformation. ${ }^{16,22)}$ These shear band-particle interactions also play a dominant role in the suppression of crack initiation, ${ }^{17)}$ leading to the increases in $\varepsilon_{\mathrm{p}}$ and $\sigma_{\mathrm{f}}$ of the composites.

As mentioned above, the shear bands are generated in the glassy matrix and Ta-rich particles interface region, and their propagation is also inhibited by Ta-rich dendrites. Here, one can notice a close relationship between the density of shear bands and the plasticity of the composites after compression test, as shown in Figs. 4 and 6. However, the $\sigma_{\mathrm{f}}$ and $\varepsilon_{\mathrm{p}}$ significantly decrease for the alloys containing Ta contents of 12 at $\%$, accompanying nearly zero plastic strain. This is presumably because the crystalline phases are precipitated in the glassy matrix, and the volume fraction of the glassy matrix phase is decreased, leading to the lose of ductility for the composite. ${ }^{23)}$ This result is consistent with that obtained form the BMG composites containing $\mathrm{ZrC}$ particles. ${ }^{15,23)}$

\section{Summary}

In situ BMG composites containing homogeneously dispersed Ta-rich and Al-free dendrite particles were fabricated for the as-cast $\left(\mathrm{Zr}_{0.5} \mathrm{Cu}_{0.4} \mathrm{Al}_{0.1}\right)_{100-x} \mathrm{Ta}_{x}(x=3-12)$ alloys. The volume fraction of the dendrite particles in- 
creases with increasing Ta content, while other crystalline phases are precipitated at Ta contents of over 9 at $\%$. The Ta concentration of the dendrite phase gradually decreases with increasing volume fraction of the dendrite particle, accompanying the gradual increase in Ta concentration in the glassy matrix. The $T_{g}$ and $T_{x}$ of the glassy matrix increase with increasing Ta concentration, while the $\Delta T_{x}$ monotonously decreases. The plasticity and strength of the BMG composites remarkably increased with increasing Ta content to 9 at $\%$, and the larger values of $\sigma_{\mathrm{f}}$ and $\varepsilon_{\mathrm{p}}$ were obtained in the Ta content range of 6 to 9 at $\%$. The $\sigma_{\mathrm{f}}$ and $\varepsilon_{\mathrm{p}}$ are $2175 \mathrm{MPa}$ and $12.5 \%$, respectively, for the 6 at $\% \mathrm{Ta}$ alloy and $2180 \mathrm{MPa}$ and $15.9 \%$, respectively, for the 9 at $\% \mathrm{Ta}$ alloy. The $\sigma_{\mathrm{f}}$ and $\varepsilon_{\mathrm{p}}$ significantly decreased with further increasing Ta content. The nearly zero $\varepsilon_{\mathrm{f}}$ with $\sigma_{\mathrm{f}}$ of $1820 \mathrm{MPa}$ was obtained for the 12 at $\%$ Ta alloy. The improvement of plasticity is attributed to an increase in the density of shear bands before final fracture resulting from the increase of the fracture strength.

\section{Acknowledgements}

This work was financially supported by Development Project on Advanced Metallic Glasses, Inorganic Materials and Joining Technology from the Ministry of Education, Science, Sports, and Culture of Japan.

\section{REFERENCES}

1) A. Inoue, K. Kita, T. Zhang and T. Masumoto: Mater. Trans., JIM 30 (1989) 722-725.
2) S. Kim, A. Inoue and T. Masumoto: Mater. Trans., JIM 31 (1990) 929934.

3) A. Inoue, T. Zhang and T. Masumoto: Mater. Trans., JIM 31 (1990) 177-183.

4) A. Peker and W. L. Johnson: Appl. Phys. Lett. 63 (1993) 2342-2344.

5) A. Inoue: Acta Metall. 48 (2000) 6089-6093.

6) C. Fan, A. Takeuchi and A. Inoue: Mater. Trans., JIM 40 (1999) 42-45.

7) C. Fan and A. Inoue: Appl. Phys. Lett. 77 (2000) 46-48.

8) H. Kato and A. Inoue: Mater. Trans., JIM 38 (1997) 793-800.

9) H. Choi-Yim, R. Busch, U. Koster and W. L. Johnson: Acta Mater. 47 (1999) 2455-2462.

10) R. B. Dandliker, R. D. Conner and W. L. Johnson: J. Mater. Res. 13 (1998) 2896-2901.

11) M. Calin, J. Ecker and L. Schultz: Scripta. Mater. 48 (2003) 653-658.

12) Q. S. Zhang, W. Zhang, G. Q. Xie, K. Nakayama, H. Kimura and A. Inoue: J. Alloys and Compounds. (2006) in press.

13) A. Inoue, W. Zhang, T. Tsurui, A. R. Yavari and A. L. Greer: Philosophical Magazine Letters. 85 (2005) 221-229.

14) C. C. Hays, C. P. Kim and W. L. Johnson: Phys. Rev. Lett. 84 (2000) 2901-2903.

15) T. Hirano, H. Kato, A. Matsuo, Y. Kawamura and A. Inoue: Mater. Trans., JIM 41 (2000) 1454-1459.

16) C. Fan, R. T. Ott and T. C. Hufnagels: Appl. Phys. Lett. 84 (2002) 1020-1022.

17) T. C. Hufnagels, C. Fan, R. T. Ott, J. Li and S. Brennan: Intermetallic. 10 (2002) 1163-1166.

18) Y. C. Kim, D. H. Kim and J. C. Lee: Mater. Trans. 44 (2003) 22242227.

19) C. Qin, W. Zhang, H. Kimura and A. Inoue: Mater. Trans. 45 (2004) 2936-2940.

20) A. Inoue: Mater. Trans., JIM 36 (1995) 866-875.

21) F. R. de Boer, R. Boom, W. C. M. Mattens, A. R. Miedema and A. K. Niessen: Cohesion in Metals, (North-Holland, Amsterdam, 1988).

22) C. Fan, L. Kecskes, T. Jiao, H. Choo, A. Inoue and P. Liaw: Mater. Trans. 47 (2006) 817-820.

23) H. Kato, D. V. Louzguine, A. Inoue and S. I. Hong: J. Metastable and Nanocrystalline Materials 24-25 (2005) 117-120. 